\title{
Letters
}

Website: bmj.com

Email: letters@bmj.com

\section{War on the roads}

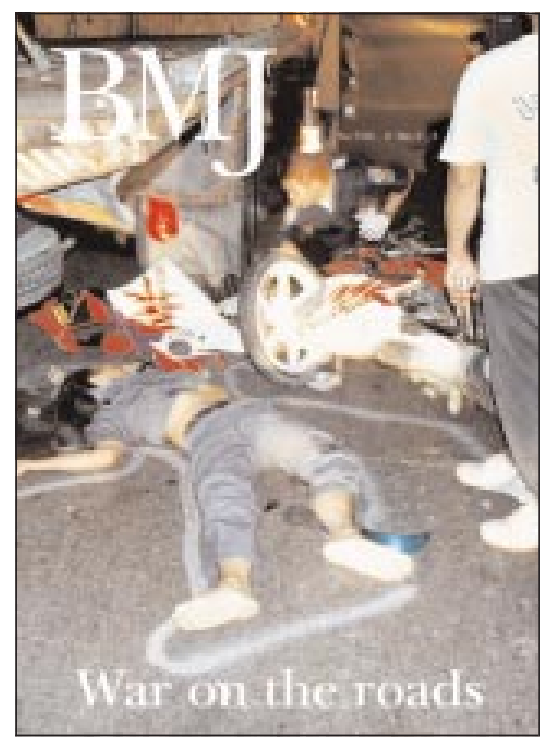

Major change is needed in politicians' and developers' attitudes

EDIToR-The articles about war on the roads in the journal of $11 \mathrm{May}^{1}$ have given prominence to the plight of vulnerable road users and the need to return the streets to the people in poorer countries. ${ }^{2}$ They have given less prominence, however, to similar needs in developed countries.

The United Kingdom has for many years had one of the best records in the world for reducing road traffic crashes. The one big anomaly has been in accidents to pedestrians. Steady progress has been made in reducing deaths and injuries to child pedestrians since the early 1970s, but the country is still placed only 15 th out of the 29 countries listed in the most recent edition of Road Accidents Great Britain 2000.

The reason for its poor position lies mainly with the design of the urban environment. Although some good progress has been made-most notably with the development of "home zones" - the United Kingdom still falls a long way behind its European neighbours in making its urban environment safe for children.

Some 20 years ago we described the enlightened approach being taken by the Scandinavians and the Dutch in creating urban environments that were friendly to vulnerable road users. ${ }^{5}$ The Dutch had "living streets," while the Scandinavians had mini village complexes with walkways and cycleways, green belts, play spaces, crèches, and shops all within easy and pleasant access (free of motor vehicles) of the residential areas.

In contrast, the United Kingdom has continued to build tightly packed housing estates with fast moving vehicles and potential walkways and cycleways blocked off for security reasons. It has signs saying "no ball games" on the sparse green areas and playgrounds sited out of sight. No wonder our children spend most of their time watching television. When they come out to play they face a hostile environment

If we are to make further progress in reducing the high pedestrian death and injury rates we need a major change in attitude from our politicians, planners, and developers. We need to give top priority to vulnerable road users and severely restrict motorists in all urban areas. We need some enlightened planning to redesign and rebuild all our depressed urban areas in a way that may prove more cost beneficial than all the other remedial measures put together. Only then can we change our position in the middle rankings of pedestrian safety to somewhere near the top.

J Gordon Avery retired public health physician Penny Avery

The Beeches, 56 Kenilworth Road, Leamington Spa, Warwickshire CV32 6JW pennyandgordonavery@yahoo.co.uk

1 Editor's choice: Toxic complacency. BMJ 2002;324. (1 May.)

2 Tiwari G. Returning streets to the people. $B M J$ 2002;324:1164. (11 May.)

3 Department for Transport, Local Government and the Regions. Road accidents Great Britain 2000. London: DTLGR, 2000

4 Biddulph M. Home zones: a planning and design handbook. London: Policy Press, 2001.

5 Avery JG, Avery PJ. Scandinavian and Dutch lessons in 5 Avery JG, Avery PJ. Scandinavian and Dutch lessons in $1982 \cdot 285 \cdot 621-6$

This war is sapping NHS of resources and inflicting untold grief

EDITOR-Analyse the assumptions that drivers make when they complain about road safety campaigns and you must conclude that drivers believe that they and their business are inherently more important than the lives of anyone on foot. There is no other explanation for their attitudes. Scratch a driver and you find someone who really believes-perhaps without even realising it-that he or she has the right to kill people who happen to be in the wrong place at the wrong time.
How else do you explain the way that one acquaintance told me about a neighbour's recent experience? The neighbour had turned too fast around a corner and run into two young girls on a crossing. One was killed, the other badly injured. "Poor chap," said the man. "He didn't stand a chance."

No thought of the chances of the children in the neighbour's path. You can be certain that he faced a fine and that the girls' parents wished they had got away as lightly.

This is a British problem. Walk around Vancouver, or Detroit, or even southern Portugal and most drivers will let you cross the road they are turning into-as is still provided by law in the United Kingdom but universally ignored. Drivers in these and other places tend to treat people on foot as no different from themselves.

Perhaps as a legacy of the days when the gentry drove round in carriages, generations of British schoolchildren have been indoctrinated to defer to drivers. If they so much as hear a car, they are told, they should wait until it goes by.

The lesson is that the police and others who indoctrinate children this way are not teaching pedestrians, they are teaching tomorrow's drivers. When these children pass their driving tests they expect to inherit a level of abjection no civilised society should tolerate.

\section{Advice to authors}

We prefer to receive all responses electronically, sent directly to our website. Processing your letter will be delayed unless it arrives in an electronic form.

We are now posting all direct submissions to our website within 24 hours of receipt and our intention is to post all other electronic submissions there as well. All responses will be eligible for publication in the paper journal.

Responses should be under 400 words and relate to articles published in the preceding month. They should include $\leqslant 5$ references, in the Vancouver style, including one to the BMJ article to which they relate. We welcome illustrations.

Please supply each author's current appointment and full address, and a phone or fax number or email address for the corresponding author. We ask authors to declare any competing interest. Please send a stamped addressed envelope if you would like to know whether your letter has been accepted or rejected.

Letters will be edited and may be shortened.

bmj.com

letters@bmj.com 
Surely drivers who don't accept a duty of care to other road users and who drive without regard for the safety of others are unwell, whatever the medical term. If you doubt this, think what would happen if they acted similarly in any context other than a conflict between driver and pedestrian or cyclist.

It is a matter that needs to be emphasised in the $B M J$ because, whatever the (under-reported) statistics tell us, the undeclared war on child and other pedestrians is sapping the NHS of resources and inflicting untold grief among the rest of us.

John Dwyer freelance writer

241 Lower Road, Great Bookham, Surrey

KT23 4DH

jhndwyer@aol.com

\section{Driving less would reduce so many problems in so many countries}

EDITOR-Bravo to the $B M J$ for reporting a massive public health problem that most publications are afraid to touch.

In Canada cars have killed more people than all the wars of the past 100 years combined. ${ }^{2}$ That's just the crashes. Air pollution from cars kills 3000-11000 Canadians a year (www.ec.gc.ca/air/ introduction e.cfm; www.oma.org/phealth/ icap.htm\#summary). ${ }^{3}$ When crashes and air pollution are combined, cars kill about 125-273 Canadians every week. Compare this with the Solicitor General of Canada's figures of 1-2 deaths a week from murder (http://web.mala.bc.ca/crim/stats/homicide. $\mathrm{htm}$ ) and 0-1 deaths a week from terrorism.

Sadly, oil addiction is not regarded by the Canadian government as worthy of serious action. While the government is spending huge sums and passing much legislation to deal with the terrorist threat, it is wavering on ratifying the Kyoto protocol on climate change.

Oil addiction in the First World also creates public health risks in other countries, as local populations are mistreated by oil companies and their friends in government. Their problems often ricochet back to the First World-as the Canadian minister of environment and energy recognised recently, stating: "When I am asked what an individual can do to fight terrorism, I say the answer is simple: drive less."

David S Thompson executive director BEST (Better Environmentally Sound Transportation), Vancouver, British Columbia, Canada V6B 1L8

www.best.bc.ca

1 Editor's choice: Toxic complacency. BMJ 2002;324. (11 May.)

2 Allen P. Remember sacrifices of war; reflect on peacetime. Winnipeg: Manitoba Public Insurance, 2000. (Available at www.mpi.mb.ca/pdfs/RW_Nov10_00.pdf)

3 David Suzuki Foundation_ Taking our breath awcra: the health effects of air pollution and climate change. Vancouver: DSF 1998: 32 .

\section{Transport has so many health} implications that must be considered

EDITOR-Motoring is dangerous. In the United Kingdom, 3500 road deaths each year compare with 3000 deaths over the entire 175 years that railways have existed.
Safety engineering-seat belts, ABS brakes, and the like-is directed at protecting motorists from themselves, but Wilde's theory of risk homoeostasis predicts that the protection becomes nullified by riskier behaviour. ${ }^{1}$ Pertinent evidence is broadly supportive. For example, speed in built up areas in the United Kingdom increased from $28 \mathrm{mph}(45 \mathrm{~km} / \mathrm{h}$ ) in 1981 (before compulsory use of seat belts) to $33 \mathrm{mph}$ (53 $\mathrm{km} / \mathrm{h}$ ) in $1997,{ }^{2}$ more than nullifying the advantage of seat belts." Whether one accepts Wilde's argument in full, the assertion by Robertson and Pless that safety engineering has no untoward effects is plainly wrong.

Furthermore, there are issues beyond injuries to motorists. The road network cannot cope with increasing traffic, no matter how much money is pumped in. There should be little surprise: the safe stopping distances given in the Highway Code show the immense space requirements of cars. Of equal importance are health issues arising from sedentary lifestyles that depend on cars. When coupled with treating victims of crashes, the increasing costs of these health issues must be a major factor in the parlous state of the NHS

So let's increase public transport. But issues need to be addressed here too. One issue is the hostility of an entrenched motoring lobby. ${ }^{4}$ Another presents a paradox: increased use of public transport inevitably leads to increased walking and cycling, if only to access public transport at railway stations and bus stops. That's good for general health. But children are rarely permitted to walk or cycle to school because of the danger posed by motoring, and similar attitudes probably affect all age groups. ${ }^{5}$ The faster driving encouraged by safety engineering seriously impinges on the rights and safety of non-motorists.

To break out of this paradox, we may have to attend to different aspects of risk. Wilde points to incentives for safer driving. I incline to the opposite: disincentives for unsafe driving. Behavioural principles suggest that disincentives must be chosen carefully-for example, fines seem ineffective. Instead, given that most drivers regard use of their car as essential, forfeiture of this privilege must shape motoring behaviour. We have increasingly reliable and cheap technologies ("black boxes" in vehicles, and roadside cameras) to record speed. Given political and societal will, we might learn to use them effectively.

Tony H Reinhardt-Rutland reader in psychology University of Ulster, Newtownabbey BT37 0OB ah.reinhardt-rutland@ulst.ac.uk

1 Wilde GJS, Robertson LS, Pless IB. Does risk homoeostasi theory have implications for road safety? $B M$ 2002;324:1149-52. (11 Mav.)

2 Reinhardt-Rutland AH. Seat-belts and behavioural adaptation: the loss of looming as a negative reinforcer. Safet Sci 2001;39:145-55.

3 Hyden C, Varhelyi A. The effects of safety, time consumption and environment of large scale use of roundabouts in an urban area: a case study Accid Anal Prev 2000:32:11-23. Reinhardt-Rutland AH Roadside speed-cameras: arguments for covert siting. Police J 200 1;74:312-5.

5 Davis $\mathrm{R}$ Coffman A Safe roads for all York: Institute of High

\section{People at risk get hit by traffic}

EDITOR-Nantulya and Reich give a clear view of the traffic conditions in different countries. The people most involved in accidents are those on the streets. ${ }^{1}$ This could have been illustrated by photographs of the typical traffic conditions in the various countries cited. In the United States one would see vast numbers of cars with single users. In Los Angeles, while I was walking down a street, a passing police car stopped to ask whether my car had broken down and I needed help. The pedestrian there is an anomaly. It is not surprising that few pedestrians are involved in accidents and that most victims are drivers. There is nothing much else to hit

On the other hand, in Ho Chi Minh City (Saigon), there are three million mopeds for nine million inhabitants. Cars are few. Finding 62\% of motorcycles involved in crashes is not surprising: a typical street photograph would show a mass of mopeds (usually with several passengers) and bicycles, with one or two cars and a few very full minibuses. It is hard to hit anything other than a moped.

Though I have never been to Kenya, Africa, or India, the pictures and films I have seen of them tend to show large crowds of pedestrians and overflowing buses or cars: the proportion of drivers to non-drivers is low. The probability of hitting another driver is much lower than that of hitting a pedestrian or a passenger.

The profile of the victims is really a reflection of the traffic conditions in a given country. Is the solution to developing countries' victim profiles to develop an American-style road scene, with the ensuing pollution, energy waste, etc?

Nicholas Moore professor of clinical pharmacology University of Bordeaux 33076, France nicholas.moore@pharmaco.u-bordeaux2.fi 1 Nantulya VM, Reich MR. The neglected epidemic: road
traffic injuries in developing countries. BMJ 2002;324:1139-41. (11 May.)

\section{Evidence based prevention of these injuries is necessary}

EDITOR-Nantulya and Reich discuss road traffic injuries in developing countries, ${ }^{1}$ and yet it is critical to understand the evidence base behind their argument.

On an aggregate global level, road traffic injuries disproportionately affect the developing world. These global data, however, are based on a dearth of nationally representative information on traffic injuries from developing countries. Our current knowledge base rests on small studies and special surveillance systems, with a few examples of survey data. ${ }^{2}$ Better national data are required to assess the true magnitude and distribution of the problem and to convince policy makers.

National resources are limited in developing countries, and programmes compete for resources. The proportion of death and disability attributable to injuries overall, and traffic injuries in particular, has been increasing over time. ${ }^{3}$ This, combined with 
the potential prevention of this loss of life and health, makes a powerful rationale for determining policy and for resource investments.

Interventions are available in the developed world, and yet their effectiveness has not been tested in developing countries. The cost effectiveness of interventions and their acceptability to the community remain unknown in the developing world. These issues need to be answered as we plan prevention and control in developing countries.

I disagree with Nantulya and Reich about the impact of corruption. This is not specific to traffic injuries or the main cause of the problem, and the chances of decreasing corruption are small. It has been argued that corruption may serve an inhibitory role as drivers end up paying police rather than paying fines. It is critical to focus on those factors that are both amenable to change and responsible for the largest share of the injury burden.

High numbers of crashes, multiple deaths per crash, and the high mortality of traffic injuries in the developing world make it important to prevent crashes. ${ }^{4}$ Although primary prevention would be most effective, interventions after the event must be considered. There are no structured assessments of national emergency medical systems; reports from single or selected facilities provide some sense of the inadequacies of acute care in the developing world but are unable to generalise. ${ }^{5}$ It is important to use systematic methods to assess pre-hospital and hospital care and plan interventions.

We are witnessing a different epidemiological transition in the developing world. Infectious diseases have not been conquered; chronic conditions are common; and the burden of injuries and violence is rising. Road traffic injuries are a risk not only to health but also to overall development. It is time for us to use evidence before we lose more lives.

Adnan A Hyder assistant professor

Johns Hopkins Bloomberg School of Public Health, Baltimore, MD 21205, USA

ahyder@jhsph.edu

1 Nantulya VM, Reich MR.The neglected epidemic: road traffic injuries in developing countries. BMJ traffic injuries in deve
2002;324:1139-41. (11 Mav.)

2 Ghaffar A, Siddiqui S, Shahab S, Hyder A. National injury survey of Pakistan. Islamabad: Health Services Academy, survey 2001.

3 Hyder AA, Morrow RH. Applying burden of disease methods in developing countries: a case study of Pakistan. Am J Public Health 2000;90:1235.

4 Hyder AA, Ghaffar A, Masud T. Motor vehicle crashes in Pakistan: the emerging epidemic. Injury Prevention 2000;6:199

5 London JA, Mock CN, Quansah RE, Abantanga FA, Jurkovich GJ. Priorities for improving hospital-based trauma care in an African city.J Trauma 2001;51:747-53.

Travel on roads 100 years ago was not as easy as nostalgia suggests

EDITOR-When we see the appalling mortality from road traffic and the constant traffic jams of today it is easy to yearn for a return to horses and carriages, when travel was slower but safer and traffic jams unknown. ${ }^{1}$ In fact, such nostalgia would be wholly misplaced.

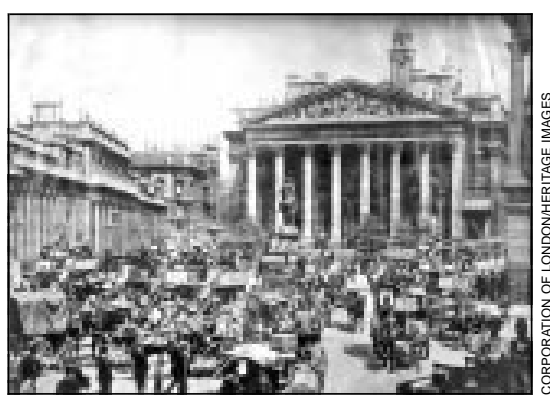

Horse driven transport was a public danger in the 1900s

By the early 1900s there were over 100000 public passenger vehicles and cabs, around half a million trade vehicles, and around half a million private carriages in Britain. In London and other large cities traffic was grinding to a halt because of traffic jams and stabling could not keep pace with the increasing number of horses; the towns of England had to deal with an estimated 10 million tonnes of horse manure a year. Horses and carriages were noisier than cars, not quieter, so that straw was placed on roads outside hospitals and the homes of the sick to muffle the rattle of iron wheels.

And what about safety? In England and Wales in 1905 there were 2424 road deaths from horses and vehicles - a rate of roughly 70 per million population. This is close to the mortality from road traffic crashes today. Of course the comparison is far from exact: we have no data on serious injuries in the early 1900 s, and many people who died then from injuries would almost certainly have been saved today. But if we express road transport mortality in terms of road deaths per 1000 vehicles on the road, horses and carriages were undoubtedly a greater danger to the public in 1900 than were motor vehicles in $2000 .{ }^{2}$

The introduction of motor cars (slowly at first but rapidly from about 1905) was seen as the answer to the problems of horse driven transport. There would be no traffic jams because cars and lorries took up less road space than carriages and horse drawn wagons did. Cars would be faster but safer because they did not bolt or swerve unpredictably, were easier to control, and were better able to brake in an emergency; and cars produced no manure.

For people such as doctors the capital cost and running costs of a car were much lower than those for horse drawn transport Moreover, cars enabled general practitioners to visit far more patients a day with much less exhaustion. No one in 1900 could have imagined the problems of road transport we have today.

Irvine S L Loudon medical historian

The Mill House, Wantage, Oxfordshire OX12 9EH irvine.loudon@wuhmo.ox.ac.uk

\footnotetext{
1 Editor's choice: Toxic complacency. BMJ 2002;324. (11 May.)

2 Loudon I. Doctors and their transport, 1750-1914. Med Hist 2001;45:185-206.
}

Prehospital care for road traffic casualties

\section{Untrained doctors' first aid kit is simple}

EDITOR-Coats and Davies make the point in their article that the prehospital arena is not an area where untrained and inexperienced doctors can be expected to perform at a high level. ${ }^{1}$ The point is also made, however, that all doctors may expect to pass or come across motor vehicle accidents during their lifetime and should be able to provide at least good quality first aid until other emergency services arrive at the scene. What equipment is required to enable the inexperienced doctor to provide this first aid?

Most preventable trauma deaths occurring before the emergency services arrive are caused by an obstructed airway. Many doctors carry pieces of equipment and kit just in case something happensintravenous cannulae or drips, for example-but in reality, surprisingly little equipment is required.

- A high visibility jacket is essential.

- A supply of latex gloves will enable airways to be cleared and opened and pressure to be applied to bleeding points.

- A pocket mask will enable ventilatory support to be given to apnoeic patients (whether due to trauma or medical causes).

Medical practitioners can rely on all other supplies coming in the ambulance response. This equipment will enable a doctor to save most salvageable trauma patients likely to die in the time between an accident occurring and an ambulance arriving, and I would recommend it as being cheap, easily acquired, and with a long life.

Mark J Coates associate specialist

Accident and Emergency, Rochdale Infirmary, Rochdale OL12 0NB

mark@coates999.supanet.com

MC is a member of Med-ALERT (All Lancashire Emergency Response Team).

1 Coats TJ, Davies G. Prehospital care for road traffic casualties. BMJ 2002;324:1135-8. (11 May.)

\section{Doctors should offer themselves as a resource}

EDITOR-I applaud Coats and Davies for their article advising how doctors should assist at road traffic crashes. ${ }^{1}$ They say that safety is key, so emergency services should be called if this has not been done, and they further highlight the need to state precise location details to the emergency services.

I would like to supplement their advice with the following suggestions.

Consider obtaining a high visibility jacket and a doctor's green flashing beacon as additions to your car's medical kit.

When assessing safety at an incident: firstly, if an emergency service vehicle is "protecting" the scene of the accident, one should drive past the scene and walk back (keeping out of the way of traffic). Secondly, the person who is first on the scene should assess whether it would be safer to use one's own vehicle to "protect the scene," especially 
if the vehicle can be placed where very visible with a warning device such as a doctor's green flashing beacon. One needs to weigh up the risk of one's own vehicle being struck against the protection afforded to rescuers and the incident scene.

Using the emergency telephone on the hard shoulder of the motorway gives a fixed location unlike a mobile phone.

When a mobile telephone is used, precise location details become essential, as although the number is passed to the emergency services, location cannot be derived from the mobile's number alone. Although the memorable 999 has been in use in the United Kingdom for longer than 112, there is a theoretical advantage to using 112 from a mobile. If the cellular base transmission station is full, a 999 call will fail as the station has no space for it. The global standard specification for mobile phones calls for the station to replace an existing non-112 call with the 112 call instead, so a 112 call may succeed where a 999 call fails.

Since paramedics can be wary of doctors offering assistance in the street, one should, first, offer identification-confirming one's qualifications; second, give them an indication of one's level of expertise; and, third, make it plain one respects their skills and specialisation in prehospital care. In practice, I try to present myself as a resource they can use, for example using a bougie at a difficult intubation, where their protocols do not allow them such, or using ketorolac (unavailable to paramedics) for analgesia.

B Salkin locum appointment for training specialist registrar

Medical Microbiology, Exeter Public Health

Laboratory, Exeter EX2 5AD

BS is a member of a voluntary aid society, undertaking occasional duties with them on an unpaid basis, and has in the past assisted on a voluntary basis at incidents he has come across while driving.

1 Coats TJ, Davies G. Prehospital care for road traffic casualties. BMJ 2002;324:1135-8. (11 May.)

\section{Spinal immobilisation should be done selectively}

EDITOR-Coats and Davies imply that all victims of motor vehicle collisions require spinal immobilisation. ${ }^{1}$ This is not true. Although immobilisation has been the standard procedure in the United States, Great Britain, and many other countries, it is not the standard worldwide. Examples of areas where spine immobilisation is not the standard are Malaysia and large portions of Australia.

Spinal immobilisation is not a benign procedure. It is uncomfortable and adds time and expense to prehospital and emergency department care. Many patients are transported to the hospital only because they are immobilised. Many of these patients receive radiographs only because they arrive immobilised or develop back pain as a result of the immobilisation. We agree with Coats and Davies that we still do not know if this is a beneficial procedure even in patients with known or high suspicion of spinal injury.

A growing body of literature indicates that trauma patients may be individually selected for immobilisation by providers of prehospital care on the basis of simple criteria. ${ }^{2-4}$ These criteria include neck pain or tenderness, reliability of the clinical examination, and neurological deficit. The National Association of Emergency Medical Services Physicians has endorsed these criteria through a position paper, and they are steadily gaining acceptance in emergency medical systems in the United States. ${ }^{5}$ It is time that we scrutinise the widespread practice of immobilising all trauma patients and adopt the more reasonable approach of selective immobilisation.

Darren Braude assistant professor of emergency medicine

University of New Mexico, ACC 4-West,

Albuquerque, New Mexico 87131, USA

Robert M Domeier emergency medical services coordinator

Saint Joseph Mercy Hospital, 4888 South Ridgeside Circle, Ann Arbor, Michigan 48105, USA

1 Coats TJ, Davies G. Prehospital care for road traffic casualties. BMJ 2002;324:1135-8. (11 May)

Domeier RM, Evans RW, Swor RA, Hancock JB, Fales W, Krohmer J, et al. The reliability of prehospital clinica evaluation for potential spine injury is not affected by the mechanism of injury. Prehosp Emerg Care 1999:3.332-7.

Stroh G, Braude D. Can an out-or-hospital cervical spine clearance protocol identify all patients with injuries? A argument for selective immobilization. Ann Emerg Med

4 Domeier RM, Swor RA, Evans RW, Krohmer J, Hancock JB, Fales W, et al. Multicenter prospective validation of pre hospital clinical spinal clearance criteria.J Trauma 2002 (in press

5 Domeier RM. Position paper, National Association of EMS Physicians. Indications for prehospital spinal immobilization. Prehosp Emerg Care 1999;3:251-3.

\section{Doctors' self rating of skills in evidence based medicine}

\section{Way that clinical epidemiology is taught} must be examined

EDITOR-Young et al suggest that Australian general practitioners may be confused about certain basic epidemiological concepts. Responsibility for some of this confusion presumably lies with whoever taught them epidemiology.

Part of the problem is suggested by the opacity and ambiguity of some of the epidemiological expert definitions against which general practitioners' knowledge was assessed. For example, for relative risk the expert definition was "Relative risk estimates the magnitude of an association between exposure and disease." So it does, but how does this definition distinguish relative risk from absolute risk?

Furthermore, for relative risk reduction the "correct" definition was "Relative risk reduction is calculated as (control event rate-experimental event rate)/control event rate)." We suspect that many epidemiologists would also "fail" if judged against this criterion, since this is not the only way in which relative risk reduction can be calculated.

Similarly, although it is true that number needed to treat is the reciprocal of the absolute risk reduction, knowledge of this fact is, arguably, irrelevant to the practical application of the concept.
The perception that epidemiology is difficult is likely to be reinforced by definitions such as these. This may intimidate nonepidemiologists from engaging in critical appraisal of research evidence. The key issue is that it is not necessary to be able to define something to be able to understand it. Furthermore, the ability to memorise a definition does not necessarily indicate understanding of the underlying concept. The emphasis in teaching epidemiology should be not on mathematical formulas but on conveying understanding and relevance for health workers. Concentrating on the mathematical aspects of the definitions may be a hindrance rather than help.

If the knowledge gap identified by Young et al is real we need to examine how we are currently teaching epidemiology. If we accept their conclusions then current methods seem to be failing.

John Macleod clinical research fellow j.a.macleod@bham.ac.uk

Jonathan Mant senior lecturer

Department of Primary Care and General Practice, University of Birmingham, Birmingham B15 2TT

1 Young JM, Glasziou P, Ward JE. General practitioners' self
ratings of skills in evidence based medicine: validation ratings of skills in evidence based
study. BMJ 2002;324:950-1. (20 April.)

\section{Editorials must be more evidence based}

EDITOR-In April the BMJ published an editorial (gently) deploring Australian general practitioners' lack of knowledge about the terminology of evidence based medicine. ${ }^{1}$ Ironically, a month earlier it published an editorial on the heart outcomes prevention evaluation (HOPE study), where the only evidence cited to support the statement that ramipril substantially decreased the risk of stroke and transient ischaemic attack was that treatment produced a $32 \%$ reduction in relative risk. ${ }^{2}$ In fact, reference to the original paper shows that the absolute risk reduction for all strokes was $1.5 \%$; in other words, 66 patients would have to take ramipril for 4.5 years to prevent one stroke, which may or may not be regarded as a clinically important effect. ${ }^{3}$

In a journal like the $B M J$, which is such a champion of evidence based medicine, surely readers have a right to expect that editorials about recent trials should contain a critical appraisal of the evidence. It should not just accept the (often overoptimistic) relative risk reduction so beloved of cardiovascular researchers and their pharmaceutical sponsors.

Hamish McLaren consultant physician Stobhill Hospital, Glasgow G21 3UW hamish.mclaren@northglasgow.scot.nhs.uk

1 Woodcock JD, Greenly S, Barton S. Doctors' knowledge about evidence based medicine terminology. BMJ 200;324:927-8. (20 April.)

2 Schrader J, Luders S. Preventing stroke. BMJ 2002;324:687-8. (23 March.)

3 Bosch J, Yusuf S, Pogue J, Sleight P, Loon E, Rangonwala B, et al. Use of ramipril in preventing stroke: double blind randomised trial. $B M J$ 2002;324:699-702. (23 March.) 


\section{General practice based interventions to prevent repeat episodes of deliberate self harm}

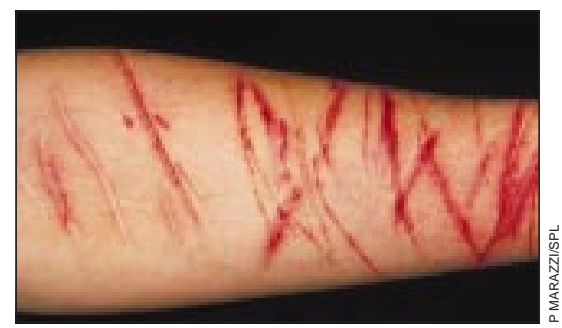

GPs have to manage this problem

EDITOR-The disappointing results of Bennewith et al's study are not particularly surprising. ${ }^{1}$ The intervention that they used (an offer of contact and an educational handout) was not beneficial in 11 previous studies. ${ }^{2}$ Indeed, no intervention has been effective in reducing future deliberate self harm, even when conducted by motivated researchers. This is probably because of the difficulty in overcoming the unpredictable future adverse circumstances of people who harm themselves.

General practitioners require a much more powerful tool than a handout to manage this complex group of patients. There is also an important methodological problem with the study concerning the population under study, as the authors have captured not only those who have made many attempts at harming themselves, whose motivation is self injury but not death, but also those who have made an unsuccessful serious suicide attempt.

The study has important lessons. Clearly most patients visit their general practitioner soon after they are discharged from the accident and emergency department with deliberate self harm, and the general practitioner is an important means of offering advice. Yet, what strategies might help general practitioners to manage this heterogeneous group of patients? One factor is how comfortable general practitioners feel in dealing with these patients. Evidence suggests that this is influenced by early exposure to psychiatry in vocational training schemes. Another variable is the efficiency of communication between hospital staff and general practitioners.

At the first point of contact the general practitioner is faced with not knowing the patient's recent history; the patient is as likely to present with physical symptoms as with mental health symptoms. ${ }^{3}$ If the patient's history is known, however, a clinician can have a high index of suspicion for mood disorder, personality disorder, or substance abuse.

In difficult cases joint work between primary and secondary care is an option, as this helps inform each party about the other's strengths. The evidence for education programmes was mentioned but dismissed by Bennewith et al because deliberate self harm is too rare to attract general practitioners' interest. But deliberate self harm is a behavioural manifestation of many disorders, of which depression and alcoholism are probably the most important reversible causes.

Importantly, many patients may initially experience considerable distress but never re-present with further episodes. So future studies should examine the effects of an intervention on the patient's mood and social function and behaviour.

There is reason to believe that general practitioners would be interested in improving their skills and knowledge about patients who harm themselves.

Alex J Mitchell lecturer in psychiatry

University of Leeds, Leeds LS2 9LN

lecturer@lineone.net

1 Bennewith O, Stocks M, Gunnell D, Peters JT, Evans MO, Sharp DJ. General practice based interventions to preven repeat episodes of deliberate self harm: cluster randomised controlled trial. BMJ 2002;324:1254-7. (25 May.) 2 Freemantle N, Harvey EL, Wolf F, Grimshaw JM, Grilli R, Bero LA. Printed educational materials: effects on professional practice and health care outcomes. Cochran Database Syst Rev 2000;(2):CD000172.

3 Crawford MJ, Wessely S. The management of patients following deliberate self-harm-what happens to those discharged from hospital to GP care? Primary Care Psychiatry 2000;6:61-5.

\section{Pictures of self injury misrepresent} published trial

EDITOR-The trial by Bennewith et al is illustrated by two striking pictures. ${ }^{1}$ One is on the front cover of the $B M J$ issue containing the paper reporting their trial and shows the forearm of somebody who has apparently cut himself or herself on severa occasions. The other image, on the This week in the BMJ page, is more artificialdepicting somebody posed as if about to cut his or her wrist-but is still about self injury. There is an irony in these choices.

Firstly, self injury (as opposed to self poisoning) was almost certainly underrepresented in the trial, in which $90 \%$ of subjects were recruited after self poisoning. Our own monitoring, and that of others, suggests that $20 \%$ of hospital attendances for self harm are due to self injury rather than to poisoning.

Secondly, although the authors indicate that there was no difference in outcomes according to method of self-harm, they do not indicate whether there was differential take up of the intervention. People who attend accident and emergency departments after self injury are more likely to leave early and less likely to receive a specialist psychosocial assessment. Their contacts with health professionals are accompanied by dissatisfaction on both sides, and it would be unsurprising if their uptake of the intervention were particularly low.

Self laceration induces a certain sort of fascination but not always much sympathy (as evidenced in at least one of the rapid responses to this paper). And yet those who harm themselves have characteristics that are associated with increasing rates of suicide in the United Kingdom (for example, younger men with alcohol or substance misuse are over-represented).

What this trial shows is that general practice is not the place to treat self injury. What current practice descriptions tell us is that mental health services are not doing well either. There is a need for new thinking in responses to self injury, which now accounts for some 30 000-40 000 hospital attendances a year in England and Wales alone.

Judith Horrocks research psychologist

David Owens senior lecturer in psychiatry

Allan House professor of liaison psychiatry

Academic Unit of Psychiatry and Behavioura

Sciences, School of Medicine, University of Leeds,

Leeds LS2 9LT

a.o.house@leeds.ac.uk

1 Bennewith O, Stocks N, Gunnell D, Peters TJ, Evans MO, Sharp DJ. General practice based interventions to prevent repeat episodes of deliberate self harm: cluster ran-
domised controlled trial. BMJ 2002;324:1254-7. (25 May.)

\section{Management of dyspepsia should be individualised}

EDIToR-The papers by Chiba et al and McColl et al show that in the medium term a test and treat approach in dyspepsia can be as effective or better than endoscopically led management. ${ }^{12}$ However, an individualised approach remains prudent in primary care.

In the long version of the paper by Chiba et al on bmj.com (bmj.com/cgi/content/full/ $324 / 7344 / 1012$ ), $33 \%$ of people with a positive result to the initial near patient test were negative on breath testing. Such results are important in populations where the prevalence of Helicobacter pylori is relatively low. Young adults with dyspepsia have a low pre-test probability of being $\mathrm{H}$ pylori positive in most developed countries and this, as McColl et al state, alters the investigation strategies used. In such patients a positive result for $H$ pylori might well be a false positive. If the prevalence of $H$ pylori is 25\% then $11-12 \%$ of positive breath tests will be false positives, the false positive rate is $25 \%$ when serological tests are used, and with near patient tests it approaches $50 \%{ }^{3}$ Eradicating non-existent $H$ pylori is unlikely to improve dyspepsia.

Secondly, the estimated $15 \%$ of people with undifferentiated dyspepsia who actually have a peptic ulcer will benefit most from a test and treat policy. The $25 \%$ whose symptoms are related to gastro-oesophageal reflux disease are unlikely to benefit. This leaves about $60 \%$ of people who have non-ulcer dyspepsia.

If we accept the results of a Cochrane review, the number needed to treat for $H$ pylori eradication in non-ulcer dyspepsia is 15. ${ }^{4}$ Correspondence raised a number of concerns with the approach taken to produce this systematic review and its main result. In addition observational data link $H$ pylori with gastric cancer but also indicate that a lack of $H$ pylori is associated with gastro-oesophageal reflux disease, Barrett's oesophagus, and adenocarcinoma of the oesophagus and gastric cardia. ${ }^{5}$ A potential protective effect of $H$ pylori against oesophageal cancer should be considered when making test and treat decisions when at best it appears that only one person out of 15 benefits symptomatically from eradication of $H$ pylori in non-ulcer dyspepsia. $H$ pylori will be successfully eradicated in most of the 
other 14, but with unknown long term consequences.

A test and treat approach can therefore be useful in the medium term for the management of dyspepsia for some people, but alternative strategies should be discussed with patients and an informed decision made on an individual basis.

Neal Maskrey medical director neal.maskrey@talk21.com

Ruth Micklewright associate editor, $\mathrm{MeReC}$ Publications

National Prescribing Centre, The Infirmary, Liverpool L69 3GF

1 Chiba N, Veldhuyzen van Zanten SJO, Sinclair P, Ferguson RA, Escobedo S, Grace E. Treating Helicobacter pylon infection in primary care patients with uninvestigated dyspepsia: the Canadian adult dyspepsia empiric treatment-Helicobacter pylori positive (CADET- $H$ ) randomised controlled trial. BMJ 2002;324:1012-6. (27 April.) 2 McColl KEL, Murray LS, Gillen D, Walker A, Wirz A, Fletcher J, et al. Randomised trial of endoscopy with testing for Helicobacter pylori compared with non-invasive $H$ pylori testing alone in the management of dyspepsia. BMJ 2002;324:999-1002. (27 April.)

3 National Prescribing Centre. Managing dyspepsia: the role of Helicobacter pylori. MeReC Bulletin 2001;12:1-4

4 Moayyedi P, Soo S, Deeks J, Forman D, Mason J. Innes M. Moayyedi P, Soo S, Deeks J, Forman D, Mason J, Innes M. Systematic review and economic evaluation of Helicobacter pylori eradication

5 Blaser MJ. Helicobacter pylori and gastric diseases. BMJ

1998;316:1507-10.

\section{A case of mistaken muscles}

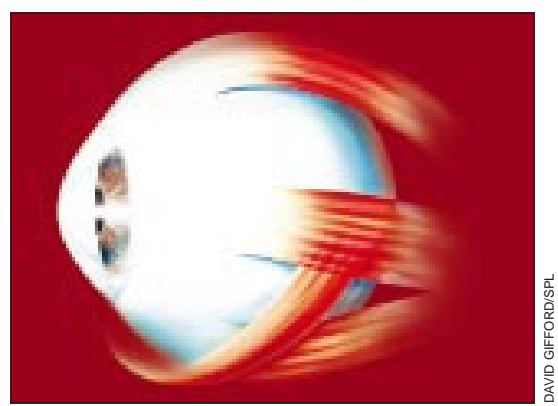

Superior oblique acting in isolation turns eye down and out

EDITOR-It was with a sense of déjà vu that I read the short piece about eye muscles. Among students and teaching staff in the department of anatomy in Cambridge we have argued this among ourselves on numerous occasions.

Our final conclusions, and what is now our policy for instruction on this muscle, is as follows. The superior oblique, acting in isolation, turns the eye down and out. However, if it was tested clinically by the patient being asked to look down and out, its action could be mimicked by the combined action of inferior and lateral recti. This is particularly so as the inferior rectus acts most effectively when the eye is abducted (looking laterally). Thus if the patient is asked to look down and in, these muscles are excluded and the problem is solved. Essentially we are testing the ability of the superior oblique to look downwards.

The confusion, which I hope the above clarifies, is compounded by some ophthalmologists being so used to testing the muscle by asking the patient to look down and in that they have forgotten that the isolated action is down and out.

Robert $\mathbf{H}$ Whitaker assistant clinical anatomist Department of Anatomy, University of Cambridge, Cambridge CB2 3DY

rhw1000@mole.bio.cam.ac.uk

1 Ahmed HU, Ali S. A case of mistaken muscles. BMJ
2002;324:962. (20 April.)

\section{Muscles do not function in isolation}

EDITOR-Ahmed and Ali wondered whether it is the oblique eye muscles or the superior or inferior recti that adduct the eye. The answer was that the obliques abduct and the recti adduct. ${ }^{1}$ Several clinic examination textbooks differed from this, but mine does not express a view. ${ }^{2}$ Gray's Anatomy was quoted as the ultimate authority.

No one knows what these muscles do in isolation. When each eve muscle functions normally the end result is a complex interaction involving six muscles. When one or more of the eye nerves or muscle(s) function less well than normal the end result is the combination of failure of the muscle(s) involved plus the unopposed action of other muscles. It is thus not possible to extract unqualified statements about the action of an individua muscle as though it functions in isolation.

What can be said is a qualified statement that when the eye is abducted the superior and inferior recti elevate or depress it, and when the eye is adducted the superior oblique depresses it and the inferior oblique elevates it (even the lateral and medial recti, if their action could be considered in isolation, would not just abduct and adduct it)

Philip D Welsby consultant physician

Western General Hospital, Edinburgh EH4 2XU P.Welsby@ed.ac.uk

I Ahmed HU, Ali S. A case of mistaken muscles. $B M J$ 2002;324:962. (20 April.)

Welsby PD. Clinical history taking and examination. Edinburgh: Churchill Livingstone, 1996.

\section{Textbooks show oblique ambiguity}

EDITOR-I was surprised that Ahmed and Ali's anatomical and clinical textbooks disagreed about the action of superior and inferior obliques. ${ }^{1}$ They allege that the anatomists describe abduction of the eye and the clinicians describe adduction by the obliques.

As the authors suggested, I challenged their authority by looking it up for myself. I found that some clinical textbooks could indeed be ambiguous. While the anatomy books were clear that the superior oblique moves the eyes down and out, the clinical books maintain that the test for 4 th nerve function is to look in and down.

Clarity was achieved by consulting the texts that were recommended when I was a student 10 years ago. To paraphrase Last's Anatomy: "the superior oblique turns it down and out; ... however, it is important to note that the ... depressing action of the superior oblique only becomes effective when the eye is turned in; the more the eye is turned out the less is its contribution to the down movement."

Talley and O'Connor's Clinical Examination reads: "turn the eye in and then try to look down: a lesion results in paralysis of downwards (and outward) movement."

It seems that there is no contradiction: the anatomist is interested in the direction of the muscle's pull (down and out, and some torsion). But the clinician is interested in how best to test the function of that muscle and so wants the eye to be looking in before asking the patient to look down. The mystery is solved.

Giles N Cattermole specialist registrar in emergency medicine

University Hospital of Wales, Cardiff CF14 4XW cattermole@doctors.org.uk

1 Ahmed HU, Ali S. A case of mistaken muscles. BM 2002;324:962. (20 April.)

2 McMinn RMH, ed Last's anatomy. 9th ed. Edinburgh: Churchill Livingstone, 1994: 514-5.

3 Talley NJ. O'Connor S. Clinical examination. 2nd ed. Oxford: Blackwell, 1992: 330.

\section{Similar problems have arisen with structure of fetal haemoglobin}

EDITOR-The experience of Ahmed and Ali is unfortunately not unique. ${ }^{1}$ One of us (AJ) was recently discussing the structure of fetal haemoglobin with a group of third year biomedical science students. Two genes code for the $\gamma$ chain of fetal haemoglobin, gA and gG. gA produces a $\gamma$ chain with an alanine at position 136, while gG produces a $\gamma$ chain with a different amino acid at position 136, but which one?

AJ told the audience that the amino acid was glutamic acid, but after the lecture KB contacted AJ and reported that her textbook states that it is glycine. AJ checked a popular haematology textbook, which clearly stated that the amino acid was glutamic acid, but on checking other textbooks he found that others reported that the amino acid was glycine.

KY and AJ then checked several textbooks and found that there was indeed some confusion, some texts stating that gG produces a $\gamma$ chain with glycine at position 136 and others that it is glutamic acid at this position. Indeed, one large multiauthored "bible" of haematology had both amino acids quoted in different sections of the book. To resolve this, AJ and KY checked the nucleotide sequence of $\mathrm{gG}$ and noted that the codon at position 136 does indeed code for glycine.

We therefore endorse the conclusions of Ahmed and Ali: if in doubt, challenge and check.

A Jewell senior lecturer a.jewell@kingston.ac.uk

K Bean third year student

School of Life Sciences, Kingston University, Surrey KT1 2EE

K Yong senior lecturer in haematology

Royal Free and University College Medical School, London WC1E 6HX

1 Ahmed HU, Ali S. A case of mistaken muscles. BMJ 2002;324:962. (20 April.)

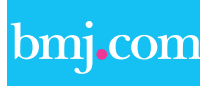

\section{Rapid responses}

Correspondence submitted electronically is available on our website 